\title{
Epidemiology of gonorrhoea in native Alaskans
}

\author{
LARRY BLACKWOOD \\ From the Health Statistics Section, Alaska Area Native Health Service, Anchorage, Alaska, USA
}

SUMMARY Data on gonococcal infections confirmed by culture show that the native population of Alaska has an incidence rate many times higher than other population groups; both sexes and all age groups are affected. In contrast to the remainder of the United States, where gonorrhoea occurs much more often in men, native Alaskan women are as likely to be infected as native Alaskan men.

\section{Introduction}

The native population of Alaska comprises three distinct racial groups: Eskimos, Indians, and Aleuts.* In 1980 these groups together numbered about 64000 people, representing $16 \%$ of Alaska's total population. The vast majority of native Alaskans live in rural communities scattered throughout the state's 586000 square miles. Many continue to live traditional subsistence-based lives with little contact with the non-native (predominantly white) population. Contact and involvement in the more dominant socioeconomic system has been, however, continually increasing.

The state of Alaska has consistently shown the highest rate of reported cases of gonorrhoea in the United States. Within the state the rate among the native population is many times that for the nonnative population. While, as with any population, the true incidence of gonorrhoea can never be determined, the observed magnitude constitutes a major morbidity problem.

\section{Source and quality of data}

Alaska has many unique characteristics, which both help and hinder the surveillance and control of gonorrhoea, particularly among the native population. With a total population of less than half a million, of which roughly 64000 are native Alaskans, the logistics associated with population

*These three groups are together referred to as "native Alaskans" throughout the paper.

Address for reprints: Mr L Blackwood, Health Statistics Section, Alaska Area Native Health Service, Box 7-741, Anchorage, Alaska 99510, USA

Accepted for publication 6 July 1981 size, when compared to the rest of the country, are more representative of a small-to-medium-sized metropolitan area than an entire state. The $\underset{\varnothing}{\varnothing}$ advantages of dealing with a small population, however, are offset by its distribution among many isolated small communities over a vast area.

At present, the state of Alaska maintains a registry $\overrightarrow{\mathscr{Q}}_{\infty}$ of all cases of gonorrhoea confirmed by culture. Data are collected through a 24-hour state-wide ${ }_{0}$ satellite call-in system and from mailed reports. The state also provides most of the culture media used and recommends surveillance protocols to health care workers. Data collected through this system $\stackrel{\varnothing}{\mathscr{Q}}$ serve as the primary comprehensive source of $\overrightarrow{\vec{A}}$ statistics for gonorrhoea for all persons in the state $\frac{\circ}{3}$ and are as complete as anywhere else in the country. The comprehensiveness of the coverage is not a result $\frac{}{0}$ of the structure of the reporting system (except to the extent that it does not cover clinical diagnoses) but rather of the care with which health workers carry out the responsibilities of reporting; this may be better than in many other areas across the country since there are fewer private laboratories in Alaska and reporting from public laboratories is generally more complete.

\section{CULTURE FACILITIES}

Most cultures for gonococci from native Alaskans originate from the seven United States Indian Health $\mathcal{N}$ Service hospitals and the Norton Sound regional $\omega$ hospital in Nome. Cultures are also performed by state public health nurses and, less often, at private or municipal clinics when native patients elect to be $\Phi$ treated at them. The most comprehensive coverage is $\stackrel{\mathcal{P}}{?}$ available for those living in or near the urban centres, where laboratory facilities are available. Those living $\frac{\vec{D}}{\mathbb{D}}$ in remote areas have to travel to urban centres for health care. Some village health workers have only 
recently been given the materials and instructions for performing cultures locally and the means of transporting them (without freezing or otherwise being destroyed) to laboratories for processing.

\section{SCREENING AND SURVEILLANCE \\ Women}

Gonococcal infections are often asymptomatic in women and are sometimes accompanied by the serious complications of pelvic inflammatory disease. Because of this the recommended method of surveillance for women attending public health care facilities or consulting public health workers (such as the IHS hospitals, state public health nurses, and municipal clinics) is that cultures for gonococci should be performed whenever a pelvic examination is carried out, regardless of the original purpose of the visit. In 1979 at Indian Health Service facilities alone, one culture was performed for every two native women of all ages. In women aged between 15 and 44 years, the most sexually active group, the number of cultures performed exceeded the number of women. While some women undergo several investigations in a year and others none, these numbers suggest that the surveillance of native women is extensive.

\section{Men}

Men are not screened as routinely as women; compared with women in the child-bearing or sexually active years they are less likely to attend on a regular basis. Also the assumption that gonorrhoea is more often symptomatic in men has resulted in less aggressive screening. Cultures are therefore performed in men only when they present with symptoms or have been identified as contacts.

\section{Estimated incidence of gonorrhoea}

While native Alaskans comprise less than $20 \%$ of the state's population, they consistently account for about half the cases of culture-confirmed gonorrhoea reported. From 1973 - the first full year of the state's surveillance programme-until 1977 the number of culture-confirmed cases of gonorrhoea among native patients increased from a little over 1600 to nearly 2700. Between 1977 and 1979 the number of cases fell slightly. In 1980 there was a sharp decline to under 2100 cases (table I). Since the number of investigations for screening carried out each year increased considerably between 1973 and 1977, the reported increase in cases during that time is probably, to a large extent, a statistical artefact rather than an indication of a change in the actual incidence of gonorrhoea. The decrease since 1977, however, has occurred despite increasing surveillance and thus suggests the beginnings of a real fall in the actual number of cases occurring in the population.
TABLE I Estimated number of cases of gonorrhoea confirmed by culture and the rate per 100000 population in native Alaskans (1973-80)

\begin{tabular}{lll}
\hline Year & No of cases & Rate \\
\hline 1973 & 1620 & 2900 \\
1974 & 1680 & 3000 \\
1975 & 1970 & 3400 \\
1976 & 2270 & 3900 \\
1977 & 2690 & 4500 \\
1978 & 2650 & 4300 \\
Male & $1300 \ddagger$ & 4130 \\
Female & $1330 \neq$ & 4390 \\
Ratio & 0.97 & 0.94 \\
1979 & 2670 & 4200 \\
Male & $1310 \ddagger$ & 4100 \\
Female & $1350 \neq$ & 4400 \\
Ratio & 0.97 & 0.93 \\
1980 & 2070 & 3200 \\
Male & $950 \neq$ & 2900 \\
Female & $110 \neq$ & 3500 \\
Ratio & 0.85 & 0.83 \\
\hline
\end{tabular}

* Includes military and civilian cases. Those of unknown race are included on the basis of the known race distribution. The number of military cases in 1978 and 1979 were estimated. Numbers are reported to three significant digits.

tRates are reported to two significant digits.

₹Civilian cases only.

\section{COMPARISON OF RATES}

A comparison of the rates for native and non-native Alaskans and the total US population is shown in fig 1. The rates for native Alaskans before 1980 are based on the population estimates of Buffler and Kraus (unpublished data); the 1980 rate uses the official census count. (All age-sex specific rates reported later use the estimates of Buffler and Kraus, (unpublished data) as demographic breakdowns by ethnic group are not yet available from the census.)

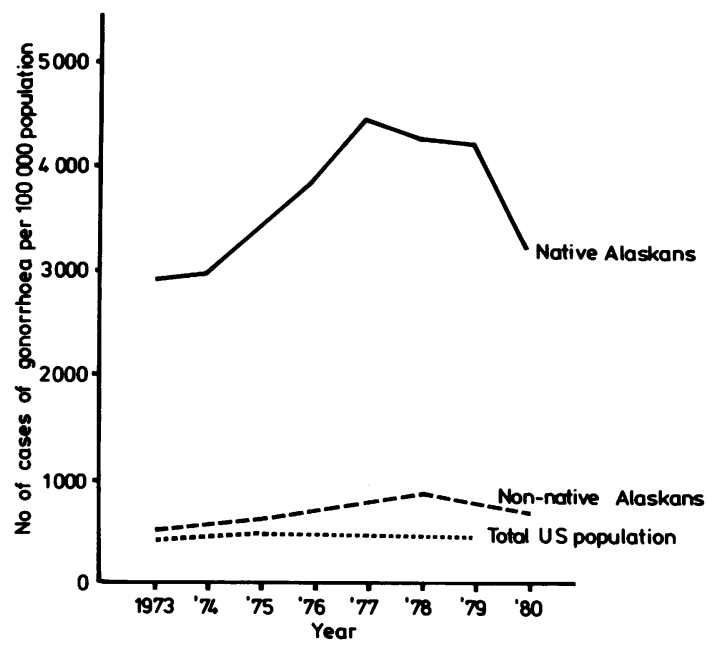

FIG 1 Estimated annual gonorrhoea incidence rates in native and non-native Alaskans and the total US population between 1973 and 1980. 
The reported incidence for gonorrhoea among native Alaskans is extremely high compared with the other population groups. The peak rate for the former of 4500 per 100000 population in 1977 contrasts with a figure of 780 for non-native Alaskans and of 470 for the total US population. The most recent rate for the native population of 3200 in 1980 reflects a $27 \%$ drop since 1977; a similar decrease of $21 \%$ occurred among non-native Alaskans since their rates peaked in 1978. Nearly the entire decrease for native Alaskans occurred between 1979 and 1980, whereas that for the non-native population occurred equally in both years since 1978 . In 1980, the rate among the former was still $4 \cdot 7$ times greater than that of $\mathbf{6 8 0}$ for the latter population and nearly seven times greater than the most recent figure avaliable for the total US population. ${ }^{1}$

\section{SEX DIFFERENCES}

The incidence of gonorrhoea is usually much higher among men than among women. The ratio of maleto-female cases in the total US population in 1979 was 1 -5:1 (based on data from the Center for Disease Control ${ }^{1}$ ) and for certain populations as high as $2: 1 .^{2}$ This pattern is evident among the non-native population in Alaska, among whom the ratio is also about $1 \cdot 5: 1$, but in native Alaskans the observed incidence in women is actually slightly higher than in men. The sex ratio for both the actual number of cases reported and the incidence rates have been under 1.0 for the years 1978-80 (table I). Because the rate in men decreased faster than that in women between 1979 and 1980 there was a notable decline in the sex ratio, making the difference from other populations even more marked.

Differences in the type of surveillance for men and women may be partly responsible for the observed ratios. Men, in whom the condition is thought to be more often symptomatic, are more likely to be treated on clinical grounds than on the results of cultures. Since only culture-confirmed cases are reported, cases diagnosed clinically are not included in the tabulations. Data collected at the largest of the Indian Health Service facilities indicate, however, that cultures are performed almost universally.

Even when these types of cases are taken into account, it is unlikely that the reported sex ratio is entirely artefactial. One possible reason for the rate among women being unusually close to that for men is that native women are much more likely to have non-native contacts than are native men. This is based on the fact that for children born with one native and one non-native parent it is much more likely that it is the mother who is native. Thus the size of the potential contact pool for women is much greater than that for men.

\section{AGE DIFFERENCES}

Age-specific rates for gonorrhoea among native Alaskans during 1980 are shown in table II and are compared with those for 1979 in fig 2. The age breakdown illustrates the extreme magnitude of the problem among certain sections of the population. In the 20-24-year-old age group there was more than one case for every 10 persons in 1980 . Because this is one of the largest and most sexually active age groups many cases occur each year, over 700 in 1980 and over 750 in each of the two previous years.

With few exceptions the reduction in rates since 1979 for both sexes combined was fairly evenly distributed by age. When the reductions are broken down by sex as well as by age, however, some distinct differences are noted. Of those age-sex groups which experienced a decline of $33 \%$ or greater the greatest decline occurred in the younger age groups of men (those aged 15-24 years) whereas for women it occurred among the older age groups (aged 30-44 years).

TABLE II Number and rate per 100000 population of cases of gonorrhoea confirmed by culture, by age and sex, in native Alaskans in 1980. (Percentage change from 1979 given in brackets.)

\begin{tabular}{|c|c|c|c|c|c|c|c|}
\hline \multirow[b]{2}{*}{$\begin{array}{l}\text { Age } \\
\text { (years) }\end{array}$} & \multicolumn{2}{|l|}{ Men } & \multicolumn{2}{|c|}{ Women } & \multicolumn{2}{|l|}{ Total } & \multirow[b]{2}{*}{$\begin{array}{l}\text { Ratio of } \\
\text { rates }(M: F)\end{array}$} \\
\hline & $\begin{array}{l}\text { No of } \\
\text { cases* }\end{array}$ & Rate $†$ & $\begin{array}{l}\text { No of } \\
\text { cases }\end{array}$ & Rate & $\begin{array}{l}\text { No of } \\
\text { cases }\end{array}$ & Rate & \\
\hline $\begin{array}{l}<15 \\
15-19 \\
20-24 \\
25-29 \\
30-34 \\
35-39 \\
40-44 \\
\geqslant 45\end{array}$ & $\begin{array}{r}1 \\
110 \\
280 \\
220 \\
140 \\
79 \\
56 \\
56\end{array}$ & $\begin{array}{c}7 \cdot 6(-3) \\
2700(-39) \\
8500(-35) \\
9000(-22) \\
8900(-23) \\
5700(-28) \\
4000(-31) \\
990(-29)\end{array}$ & $\begin{array}{r}14 \\
280 \\
390 \\
240 \\
85 \\
50 \\
24 \\
29\end{array}$ & $\begin{array}{r}120(-43) \\
7700(-21) \\
12200(-14) \\
9000(-10) \\
4700(-38) \\
3300(-35) \\
1700(-35) \\
540(-20)\end{array}$ & $\begin{array}{r}15 \\
390 \\
680 \\
460 \\
230 \\
130 \\
80 \\
85\end{array}$ & $\begin{array}{r}59(-41) \\
5100(-27) \\
10300(-24) \\
9000(-15) \\
6700(-30) \\
4400(-30) \\
2900(-31) \\
770(-23)\end{array}$ & $\begin{array}{l}0.06 \\
0.35 \\
0.70 \\
1.0 \\
1.9 \\
1.7 \\
2.4 \\
1.8\end{array}$ \\
\hline Total & 950 & $2900(-29)$ & 1110 & $3500(-20)$ & 2060 & $3200(-23)$ & 0.83 \\
\hline
\end{tabular}

* Civilian cases only. Cases of unknown race or sex are included on the basis of the known distribution. Cases are reported to two significant digits.

tRates are reported to two significant digits when under 10000 , to three if over. 


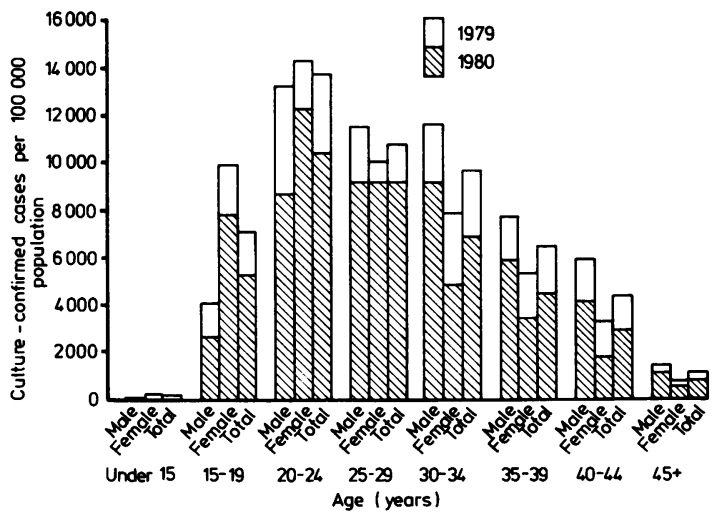

FIG 2 Gonorrhoea incidence rates by age and sex for native Alaskans (1979-80).

The ratios of rates by age and sex in native Alaskans and in the total US population in 1979 are given in table III. Except for boys under 15 years (in which virtually no cases were reported), rates among native Alaskans exceed those for the total US population in all age and sex groups. The difference increases with age, particularly for native women, whose rates are 30 times higher than for the total US population for those aged 30-34 years and more than 60 times higher for those aged $\geqslant 35$ years. While the latter difference might be due to variations in the age distribution within that group in the two populations (the mean age for those over 35 years in the native population is younger), this does not account for the differences in the other age groups.

That the greatest discrepancies in the rates exist among women is not surprising given the low overall sex ratio in native Alaskans, which is also consistently lower by age group than that for the total US population. The sex ratio increases with age among native Alaskans as it does for the total US population, but it never exceeds 3.0 compared with

TABLE III Ratio of rates by age in native Alaskans to those in total US population (1979)

\begin{tabular}{lccc}
\hline Age (years) & Men & Women & Total \\
\hline$<15$ & $0 \cdot 68$ & $5 \cdot 6$ & $4 \cdot 1$ \\
$15-19$ & $4 \cdot 6$ & $6 \cdot 7$ & $5 \cdot 8$ \\
$20-24$ & $5 \cdot 7$ & $9 \cdot 3$ & $7 \cdot 1$ \\
$25-29$ & $7 \cdot 2$ & $15 \cdot 1$ & $9 \cdot 6$ \\
$30-34$ & $13 \cdot 8$ & $30 \cdot 0$ & $17 \cdot 7$ \\
$\geqslant 35$ & $23 \cdot 8$ & $64 \cdot 9$ & $32 \cdot 7$ \\
Total & $7 \cdot 3$ & $12 \cdot 0$ & $9 \cdot 1$ \\
\hline
\end{tabular}

about 5.0 in the older age groups in the total US population.

Disregarding the magnitude of the differences in the rates the pattern by age and sex among native Alaskans shows similarities to that found in most populations. In 1980 rates peaked in the 20-24-yearold age group of women and in the 25-29-year-old group of men. (In 1979 the rates peaked in the 20-24-year-old group for both sexes). Before 25 years girls show higher rates than boys, reflecting their typically earlier sexual maturity. In the 25-29-yearold group men consistently show equal or higher rates than women. (This is a slightly different pattern from that in the total US population, in which rates for women are higher than in men only in age groups under 20 years). Rates remain relatively high for men up to 34 years whereas they begin to fall rapidly after 24 years for women. The continued high rates for men aged 25-34 years may be an artefact due to inaccurate population estimates, as the number of cases among men drops off rapidly after the age of 24 as in women.

\section{Discussion}

The incidence of gonorrhoea among native Alaskans has remained high over the last few years and affects men and women of all age groups. Not only is the incidence high in relation to other population groups in the United States, it is high when compared with indigenous populations in similar circumstances in other countries-for example, South Australia ${ }^{3}$ and the South Pacific. ${ }^{4}$ Although some recent progress in controlling the rate is evident new innovative approaches to surveillance and treatment will probably be required to reduce it to even a moderate level.

The author would like to thank Tom Kelly of the Center for Disease Control for providing the raw data and comments on an earlier draft of the paper.

\section{References}

1. Center for Disease Control. Sexually Transmitted Disease Statistical Newsletter, 1979. Washington: US Department of Health and Human Services, Public Health Service. 1979.

2. Wright RA, Judson FN. Relative and seasonal incidences of the sexually transmitted diseases: a two-year statistical review. Br J Vener Dis 1978;54:433-40.

3. Jorgensen L. Epidemiology of gonorrhoea and syphilis in South Australia (1966-77). Br J Vener Dis 1979; 55: 131-7.

4. Willcox RR. Venereal diseases in the islands of the South Pacific. Br J Vener Dis 1980;56:204-9. 